Oral Section

\title{
From Kolisko to nowadays: progresses and discoveries in agro-homeopathy
}

\author{
Giovanni Dinelli, Ilaria Marotti, Grazia Trebbi, Lucietta Betti \\ Dept.of Agroenvironmental Sciences and Technologies, University of Bologna, Italy
}

\begin{abstract}
The use of ultra-diluted preparations method in agriculture was introduced with agro-homeopathy, which allows to influence biological processes of plants by either accelerating or delaying growth. Moreover, it can contribute to the control of plagues and diseases, directly promoting an increase of the yield and an improvement of product qualitative traits. Since the pioneering works of Kolisko on wheat germination [1] and Junker on growth of microorganisms (paramecium, yeast, fungi) [2], in the last 30 years work has flourished from independent researchers from worldwide (Americas, Europe and Australasia).
\end{abstract}

The international research works on agro-homeopathy can be conceptually divided in two main groups: effects of ultra-diluted preparations on crop growth and applicability for crop disease control.

The first type of investigations usually are carried out on both healthy organisms for determining the growth stimulation of treatments and on abiotically stressed plants (i.e. heavy metal over-exposition, salt excess, water and nutrients deficiency) for determining the re-growth stimulation of ultra-dilutions $[3,4]$.

The second type of investigations are usually performed on artificially diseased organisms (i.e. fungal and viral pathogens or nematode infection), which may react more markedly to homeopathic treatments than healthy ones [5].

Unfortunately, on the basis of the extensive critical review of published papers, there is little firm evidence to support the reliability of the reported results. Except for a limited number of publications, the most common drawbacks of agro-homeopathy researches are the poor experimental methodology and the inadequate statistical analysis. Moreover, since there is no agricultural homeopathic pharmacopoeia, much work is required to find suitable remedies, potencies and dose levels.

Considering the criticism on the practical applicability of ultra-diluted preparations, in order to be accepted as a valid part of agricultural practices a well-structured research strategy for agro-homeopathy is needed. This is often hampered by methodological problems as well as by the general underinvestment on the academic and nonacademic research structures.

Fundamental researches based on collaborative approaches (i.e. ring tests on selected crop models) and on common experimental protocols (i.e. statistical robustness) are the keys for determining the worldwide acceptability of agro-homeopathy as a sustainable agro-technique.

Keywords: agro-homeopathy, ultra-diluted preparations, experimental methodology, statistical analyses 


\section{Bibliography}

[1] Kolisko L. Physiologischer und physikalischer Nachweis der Wirksamkeit kleinster Entitäten. 1923; Stuttgart, Verlag Der Kommende Tag AG.

[2] Junker H.. Die Wirkung extremer Potenzverdünnungen auf Organismen. Pflugers Arch ges Phys 1928; 219B, 5/6, 647-672.

\section{(c)) EY-NC-ND Licensed to GIRI}

Support: authors declare that this study received no funding

Conflict of interest: authors declare there is no conflict of interest

Received: 01 June 2012; Revised: 12 August 2012; Published: 30 September 2012.

Correspondence author: Giovanni Dinelli, giovanni.dinelli@unibo.it

How to cite this article: Dinelli G, Marotti I, Trebbi G, Betti L. From Kolisko to nowadays: progresses and discoveries in agro-homeopathy. Int J High Dilution Res [online]. 2012 [cited YYYY Month dd]; 11(40):122-123. Proceedings of the XXVI
GIRI
Symposium;
2012
Sep 20-22;
Florence
(Italy).
GIRI;
2012;
Available
from: 